\title{
O DIREITO FUNDAMENTAL AO BOM CONTROLE PÚBLICO
}

\section{THE FUNDAMENTAL RIGHT TO GOOD PUBLIC CONTROL}

\author{
${ }^{1}$ Adircélio De Moraes Ferreira Junior
}

\section{RESUMO}

A atuação do Poder Público se dá por meio do chamado fenômeno financeiro, por meio do qual o Estado arrecada recursos com o intuito de devolvê-los aos cidadãos por meio da prestação de serviços públicos. Dentre os valores que devem nortear essa atividade estatal, que vai desde a elaboração do orçamento até a sua execução, encontram-se a justiça financeira e o direito fundamental à boa administração e governança pública, insculpidos no texto constitucional brasileiro. Essa vinculação determina a eficiência e eficácia do agir estatal por meio de suas políticas públicas e coloca os Tribunais de Contas, como órgãos responsáveis pelo controle externo da administração pública brasileira, no papel central de promotores ou garantidores do cumprimento desses compromissos de extração constitucional. Para tanto, faz-se necessária a adoção por parte desses órgãos de uma nova concepção de controle, mais eficiente, eficaz, racional e abrangente, que pode ser traduzida na noção de bom controle público, o qual, por sua vez, deve ser reconhecido também como um direito fundamental na sociedade contemporânea. Esse novo paradigma de controle deve superar a ineficiência e ineficácia do controle tradicional, um dos vetores do déficit de legitimidade de que padecem as Cortes de Contas brasileiras, e contribuir de maneira decisiva para a concretude daqueles valores maiores, de forma que esses órgãos de controle se convertam em legítimos Tribunais da Boa Governança Pública, combatendo, assim, efetivamente as anomalias na atuação do Poder Público, causadoras de injustiças financeiras, notadamente a ineficiência, a ineficácia e a corrupção.

Palavras-chave: Direito fundamental ao bom controle público, Controle da administração pública brasileira, Cortes de contas, Tribunais da boa governança

\footnotetext{
${ }^{1}$ Mestre em Direito pela Universidade Federal de Santa Catarina - UFSC, Santa Catarina (Brasil). Conselheiro do Tribunal de Contas do Estado de Santa Catarina, Santa Catarina (Brasil). E-mail: adircelio@uol.com.br
} 


\begin{abstract}
The operation of the Government happens by so-called financial phenomenon, through which the state collects resources in order to return them to the citizens through the provision of public services. Among the values that should guide this state activity, ranging from budgeting to its implementation, are the financial justice and the fundamental right to good public administration and governance, inscribed in the Brazilian Constitution. This linking determines the efficiency and effectiveness of the acting State through its public policies and puts the Courts of Accounts, as bodies responsible for external control of the Brazilian Public Administration, in the central role of promoters or guarantors of compliance with these constitutional extraction commitments. To this end, it is necessary the adoption by these organs of a new conception of control, more efficient, effective, rational and comprehensive, which can be translated into the notion of good public control, which, in turn, should be recognized also as a fundamental right in modern society. This new paradigm of control must overcome the inefficiency and ineffectiveness of the traditional control, one of the vectors of the legitimacy deficit suffered by Brazilian Courts of Accounts, and contribute decisively to the concreteness of those higher values, so that these oversight bodies become truly Courts of Good Public Governance, thus, fighting effectively against the anomalies in the performance of the government, causers of financial inequities, especially inefficiency, ineffectiveness and corruption.
\end{abstract}

Keywords/Palabras-claves/Mots-clés: Fundamental right to good public control, Brazilian public administration control, Courts of accounts, Courts of good governance 


\section{INTRODUÇÃO}

A atividade do Estado pressupõe a existência de uma atuação financeira, que consiste na arrecadação, na administração e na destinação de recursos públicos. Esse fenômeno financeiro permite a execução das ações estatais relacionadas aos diversos fins visados pelo Poder Público.

Por não se esgotar em si mesma, essa atuação financeira tem caráter instrumental, na medida em que é por meio dela que o Poder Público consegue concretizar as demais atividades necessárias para a satisfação das demandas coletivas dos cidadãos. E como essa atividade está intimamente ligada aos próprios fins do Estado, o papel que desempenham as finanças públicas depende da própria concepção que se tem dele.

Para tanto, é necessário que a elaboração e a execução do orçamento público sejam pautadas pelo princípio da justiça financeira e pelo direito fundamental à boa administração e governança, que devem orientar toda a ação pública, desde a previsão da arrecadação da receita até a realização da despesa, impondo a eficiência e a eficácia no agir estatal, levado a efeito por meio de suas políticas públicas.

O desrespeito a essas diretrizes caracterizam injustiças financeiras que devem ser combatidas e nesse contexto os Tribunais de Contas, como órgãos titulares da função de controle externo da administração pública, assumem posição central de promotores ou garantidores desses princípios constitucionais, cuja concretização depende também de uma nova concepção de controle, mais eficiente, eficaz e racional por aquelas instituições, harmônico com as diretrizes veiculadas por essa noção de justiça e pela ideia de boa administração pública.

Essa nova ideia de controle pode ser sintetizada na expressão bom controle público, também alçado à condição de direito fundamental de extração constitucional.

Assim, os Tribunais de Contas, guardiães constitucionais das contas públicas, assumem papel central na promoção de uma justiça financeira material, e não apenas formal, devendo, com isso, incentivar a adoção de uma boa governança pública por parte de seus jurisdicionados, combatendo as anomalias da atuação estatal, geradoras de iniquidades, notadamente a ineficiência, a ineficácia e a corrupção, ainda tão presentes na administração pública brasileira. 


\section{O PRINCÍPIO DA JUSTIÇA FINANCEIRA E O DIREITO FUNDAMENTAL À BOA ADMINISTRAÇÃO E GOVERNANÇA PÚBLICA}

O conceito de justiça financeira ou orçamentária engloba, simultaneamente, os aspectos da receita e da despesa pública, transcendendo, assim, a noção de justiça tributária, a qual, por sua vez, guarda relação com a vertente da receita pública. Ele expressa, portanto, duas faces de uma mesma ideia, qual seja, a justiça das receitas e dos gastos públicos. (TORRES, 2000, p. 197)

A ideia de justiça financeira sempre esteve presente na história do pensamento jurídico, ocupando, inclusive, lugar de destaque mesmo quando diluída na concepção de justiça política ou social. (TORRES, 2000, p. 198)

É possível afirmar, portanto, que a ideia de justiça financeira reúne as noções de justiça social e fiscal e encontra seu alicerce no princípio da isonomia, atribuindo ao valor justiça uma dimensão financeira. O seu conteúdo semântico obriga o Estado Constitucional ${ }^{1}$ a perseguir a equidade na gestão financeira pública, vista sob a ótica integrada das duas frentes da atuação fiscal do Poder Público, quais sejam, a arrecadação e o gasto. (FERREIRA JÚNIOR; OLIVO, 2014, p. 204)

De maneira explícita, o princípio da justiça financeira é encontrado na nos seguintes artigos da Constituição da República Portuguesa (CRP):

\section{Artigo 81. ${ }^{\circ}$ - Incumbências prioritárias do Estado}

Incumbe prioritariamente ao Estado no âmbito económico e social:

[...]

b) Promover a justiça social, assegurar a igualdade de oportunidades e operar as necessárias correcções das desigualdades na distribuição da riqueza e do rendimento, nomeadamente através da política fiscal;

$[\ldots]$

Artigo $103 .^{\circ}$ - Sistema fiscal

1. O sistema fiscal visa a satisfação das necessidades financeiras do Estado e outras entidades públicas e uma repartição justa dos rendimentos e da riqueza.

[...] (PORTUGAL, 1976, grifo nosso)

Ao abordar o tratamento dado a esse princípio pela CRP, Costa assevera que:

A Constituição da República compromete o Estado com o objetivo de construção de uma sociedade justa, por via da promoção da justiça distributiva e retributiva.

\footnotetext{
1 Carbonell (2003, p. 9-10) lembra que o constitucionalismo contemporâneo teve a definição de seus traços característicos nos últimos cinquenta anos, principalmente a partir do pós-guerra, sem que tivesse permanecido, desde então, como um modelo estático, seguindo sua evolução em muitos sentidos. As modificações operadas sob o paradigma do Estado Constitucional são de tal magnitude que, hodiernamente, deve-se falar do Estado Neoconstitucional. É, inclusive, mais pertinente falar de vários neoconstitucionalismos e não apenas de um neoconstitucionalismo.
} 
Do discurso jurídico-constitucional resulta uma conceção sistémica de justiça, inerente à dignidade da pessoa humana, e fortemente ligada ao paradigma da liberdade igual.

A Constituição da República começa por afirmar, no seu art. 1. ${ }^{\circ}$, o seu compromisso desta com os valores da liberdade, da justiça e da solidariedade.

A justiça, enquanto valor, informa todo o ordenamento jurídico. A ela não escapa o direito financeiro público. O preceituado no art. $81 .^{\circ}$, al. b), e nos artigos $103 .^{\circ},{ }^{\circ}{ }^{\circ} 1$, e $104 .^{\circ}$ da CRP, acolhem uma certa ideia de justiça, social e fiscal, que podemos fundir numa ideia de justiça financeira. Esta traduz-se, pois, numa importante dimensão da justiça distributiva.

$\mathrm{Na}$ verdade, a problemática da justiça distributiva deve ser abordada numa perspetiva integrada de arrecadação de receita / realização de despesa pública.

É neste sentido que se pode afirmar que impostos e despesas públicas são duas faces da mesma moeda.

A arquitetura de um sistema fiscal pouco nos diz acerca da efetiva realização da justiça distributiva. Esta depende da afetação dos recursos públicos, ou seja, depende de quem vai beneficiar de tais recursos e em que medida.

$[\ldots]$

Assim, afigura-se-nos que, quando abordamos a problemática da justiça distributiva, o recurso à ideia de justiça financeira é preferível às ideias, parcelares, de justiça fiscal e de justiça social.

Os preceitos da Constituição fiscal e da Constituição social têm como denominador comum um núcleo constituído pelos valores da igualdade, da democracia e da solidariedade, a par com o valor da liberdade, postulando aquele uma justa repartição dos rendimentos e da riqueza, e estando o Estado comprometido com a sua promoção. (COSTA, 2012, p. 274-275, grifo no original)

E ao estabelecer, em seu art. 266, a vinculação da administração pública ao princípio da justiça, a CRP "sujeita-a, naturalmente, ao dever de promoção da justiça financeira". (COSTA, 2012, p. 274-275)

No Brasil, o princípio da justiça financeira pode ser extraído de diversas passagens da Constituição Federal (CRFB/88), encontrando-se implícito nos valores que constituem os fundamentos da República, como a cidadania e a dignidade da pessoa humana (art. $1^{\circ}$, II e III, da CRFB/88), assim como nos seus objetivos de construção de uma sociedade livre, justa e solidária; de erradicação da pobreza e da marginalização; de redução das desigualdades sociais e regionais e da promoção do bem de todos (art. $3^{\circ}$, I, III e IV, da CRFB/88). Ele pode ser retirado ainda do reconhecimento, contido no preâmbulo da CRFB/88, da igualdade e da própria justiça como um dos valores supremos de uma sociedade fraterna e pluralista. (FERREIRA JÚNIOR; OLIVO, 2014, p. 204-205) 
Assim, o princípio da justiça financeira pode ser retirado de diversos outros princípios dispersos na CRFB/88 (tais como o da eficiência, da eficácia, ${ }^{2}$ da moralidade, da legitimidade $^{3}$ e da economicidade ${ }^{4}$ ), devendo ser interpretado como um dos muitos compromissos constitucionais do Estado brasileiro. Esse princípio informa todo o ordenamento jurídico nacional, preconiza uma justa distribuição da riqueza produzida pelo País e deve nortear toda a atuação estatal. Além disso, ele guarda relação estreita e direta com o direito fundamental à boa administração e à boa governança.

Do ponto de vista normativo, Rodríguez-Arana Muñoz (2013, p. 39) reconhece que a existência positiva desse direito fundamental à boa administração parte da Recomendação número R (80) 2 adotada pelo Comitê de Ministros do Conselho da Europa de 11 de março de 1980, relativa ao exercício de poderes discricionários pelas autoridades administrativas, assim como da jurisprudência do Tribunal de Justiça das comunidades europeias e do Tribunal de Primeira Instância.

Entre o Conselho da Europa e a jurisprudência comunitária, a partir de 1980 foi-se construindo gradativamente o direito à boa administração pública, que a Carta dos Direitos Fundamentais da União Europeia, proclamada solenemente em Nice pelo Parlamento, pelo Conselho da União e pela Comissão Europeias, em 7 de Dezembro de $2000^{5}$, reconheceria em seu art. 41.

\footnotetext{
${ }^{2}$ Segundo Carvalho Filho (2012, p. 31), "a eficiência não se confunde com a eficácia nem com a efetividade. A eficiência transmite sentido relacionado ao modo pelo qual se processa o desempenho da atividade administrativa; a ideia diz respeito, portanto, à conduta dos agentes. Por outro lado, eficácia tem relação com os meios e instrumentos empregados pelos agentes no exercício dos seus misteres na administração; o sentido aqui é tipicamente instrumental. Finalmente, a efetividade é voltada para os resultados obtidos com as ações administrativas; sobreleva nesse aspecto a positividade dos objetivos". Para Freitas (2014, p. 23), engana-se quem acredita que, ao consagrar o princípio da eficiência em seu art. 37, a CRFB/88 excluiu o da eficácia, já que ele foi citado expressamente no art. 74. Invocando Peter Drucker, sustenta ainda que a eficácia "consiste justamente em incrementar a gestão pública, de maneira que a administração escolha fazer o que constitucionalmente deve fazer [...], em lugar de apenas fazer bem ou eficientemente aquilo que, não raro, se encontra mal concebido ou contaminado". E, inspirado na lição de Vergottini (2004, p. 544), define eficiência como o "melhor emprego dos recursos disponíveis".

3 A análise da legitimidade implica confrontar a administração da coisa pública com o sacrifício econômico imposto ao cidadão. Segundo Willeman (2008, p. 283-284), "o aspecto da legitimidade guarda íntima relação

com o fato de que as finanças públicas devem ser geridas consoante os objetivos politicamente aceitos pela

Nação. Sem dúvida alguma, o controle exercido sob o ângulo da legitimidade reveste-se de extraordinário cunho democrático, invocando a ideia de consenso para a ordem financeira".

4 Para Willeman (2008, p. 284), "a ideia de economicidade está intimamente relacionada à operacionalização com o menor custo possível". Ou seja, para se mensurar a economicidade é preciso que se investigue se não existe para um determinado gasto uma alternativa mais barata e igualmente eficaz.

5 A Carta de Nice foi incorporada posteriormente como Parte II do Tratado firmado em Roma pelos vinte e cinco

Chefes de Estado e de Governo da União Europeia em 29 de outubro de 2004, por meio do qual se estabeleceu a Constituição Europeia. No Tratado Constitucional, o direito fundamental à boa administração encontra-se numerado como art. II-101.
} 
Para Freitas, o direito fundamental à boa administração consiste no:

[...] direito fundamental à administração pública eficiente e eficaz, proporcional cumpridora de seus deveres, com transparência, sustentabilidade, motivação proporcional, imparcialidade e respeito à moralidade, à participação social e à plena responsabilidade por suas condutas omissivas e comissivas. A tal direito corresponde o dever de observar, nas relações administrativas, a cogência da totalidade dos princípios constitucionais e correspondentes prioridades.

Observado de maneira atenta, o direito fundamental à boa administração é lídimo plexo de direitos, regras e princípios, encartados numa síntese, ou seja, o somatório

de direitos subjetivos públicos. No conceito proposto, abrigam-se, entre outros, os seguintes direitos:

(a) o direito à administração pública transparente, que supõe evitar a opacidade (salvo nos casos em que o sigilo se apresentar justificável, e ainda assim não definitivamente), com especial destaque para o direito a informações inteligíveis, inclusive sobre a execução orçamentária e sobre o processo de tomada das decisões administrativas que afetarem direitos;

(b) o direito à administração pública sustentável, que implica fazer preponderar, inclusive no campo regulatório, o princípio constitucional da sustentabilidade, que determina a preponderância dos benefícios sociais, ambientais e econômicos sobre os custos diretos e indiretos (externalidades negativas), de molde a assegurar o bemestar multidimensional das gerações presentes sem impedir que as gerações futuras alcancem o próprio bem-estar multidimensional;

(c) o direito à administração pública dialógica, com amplas garantias de contraditório e ampla defesa - é dizer, respeitadora do devido processo, com duração razoável e motivação explícita, clara e congruente;

(d) o direito à administração pública imparcial e desenviesada, isto é, aquela que, evitando os desvios cognitivos, não pratica nem estimula discriminação negativa de qualquer natureza e, ao mesmo tempo, promove discriminações inversas ou positivas (redutoras das desigualdades iníquas);

(e) o direito à administração pública proba, que veda condutas éticas não universalizáveis, sem implicar moralismo ou confusão entre o legal e o moral, uma vez tais esferas se vinculam, mas são distintas;

(f) o direito à administração pública respeitadora da legalidade temperada, ou seja, que não se rende à "absolutização" irrefletida das regras;

(g) o direito à administração pública preventiva, precavida e eficaz (não apenas economicamente eficiente), eis que comprometida com resultados compatíveis com os indicadores de qualidade de vida, em horizonte de longa duração. (FREITAS, 2014, p. 21-22, grifo no original)

Esses direitos referem-se a um padrão mínimo, não excluindo outros e necessitando ser tutelados em sua totalidade, a fim de que a discricionariedade não seja utilizada contra o direito fundamental à boa administração. Para Freitas (2014, p. 23), “as escolhas administrativas serão legítimas se - e somente se - forem sistematicamente eficazes, sustentáveis, motivadas, proporcionais, transparentes, imparciais e ativadoras da participação social, da moralidade e da plena responsabilidade".

Mallén (2004, p. 104), na mesma linha, assevera que o direito a uma boa administração repercute de modo mais ou menos intenso ou difuso nas Constituições dos Estados Membros da União Europeia e que as referências a ele são, em regra, retiradas dos princípios 
constitucionais relativos à administração pública, os quais, por sua vez, encontram- se esparsos ao longo das respectivas cartas constitucionais de maneira sistemática ou não.

Ele representa uma espécie de direito-garantia ou direito-instrumental, que permite a defesa de outros direitos, não se tratando, por isso, de um direito criado, mas, sim, de novo cunho. Em outras palavras, ele é elaborado de maneira autônoma, a partir de um catálogo que dota de unidade uma gama de direitos reconhecidos de modo disperso na ordem jurídica comunitária. (MALLÉN, 2004, p. 42).

É pertinente, ainda, distinguir as noções de governança e de governabilidade. A primeira ideia está relacionada à capacidade financeira e administrativa, em sentido amplo, de um governo levar a efeito suas políticas públicas, enquanto que a segunda está ligada à capacidade política de governar. Em outras palavras, a governabilidade "seria resultante da relação de legitimidade do Estado e do seu governo com a sociedade”. (MATIAS-PEREIRA, 2009, p. 68)

A governabilidade está relacionada às próprias condições substantivas e materiais de exercício do poder e de legitimidade do Estado e do seu governo, decorrentes de sua postura diante da sociedade. É a autoridade política estatal, ou seja, a capacidade que o Estado "tem para agregar os múltiplos interesses dispersos pela sociedade e apresentar-lhes um objetivo comum para o curto, médio e longo prazo". (MATIAS-PEREIRA, 2009, p. 69)

Por sua vez, governança é a capacidade de um governo para elaborar e executar suas políticas públicas, nelas incluída a gestão das finanças públicas, com o objetivo do atendimento das demandas dos cidadãos. É um complexo processo de tomada de decisões que antecipa e transcende o governo. (MATIAS-PEREIRA, 2009, p. 69)

No setor público, a governança abrange "essencialmente os mecanismos de liderança, estratégia, e controle postos em prática para avaliar, direcionar e monitorar a atuação da gestão, com vistas à condução das políticas públicas e à prestação de serviços de interesse da sociedade"'. (TCU, 2013, p. 14)

De acordo com o Chartered Institute of Public Finance and Accountancy - CIPFA e a International Federation of Accountants - IFAC (2013), a compreensão do que vem a ser uma boa governança no setor público passa pelas seguintes diretrizes:

\footnotetext{
a) garantir a entrega de benefícios econômicos, sociais e ambientais para os cidadãos;

b) garantir que a organização seja, e pareça, responsável para com os cidadãos;

c) ter clareza acerca de quais são os produtos e serviços efetivamente prestados para cidadãos e usuários, e manter o foco nesse propósito;
} 
d) ser transparente, mantendo a sociedade informada acerca das decisões tomadas e dos riscos envolvidos;

e) possuir e utilizar informações de qualidade e mecanismos robustos de apoio às tomadas de decisão;

f) dialogar com e prestar contas à sociedade;

g) garantir a qualidade e a efetividade dos serviços prestados aos cidadãos;

h) promover o desenvolvimento contínuo da liderança e dos colaboradores;

i) definir claramente processos, papéis, responsabilidades e limites de poder e de autoridade;

j) institucionalizar estruturas adequadas de governança;

k) selecionar a liderança tendo por base aspectos como conhecimento, habilidades e atitudes (competências individuais);

1) avaliar o desempenho e a conformidade da organização e da liderança, mantendo um balanceamento adequado entre eles;

m) garantir a existência de um sistema efetivo de gestão de riscos;

n) utilizar-se de controles internos para manter os riscos em níveis adequados e aceitáveis;

o) controlar as finanças de forma atenta, robusta e responsável; e

p) prover aos cidadãos dados e informações de qualidade (confiáveis, tempestivas, relevantes e compreensíveis). (TCU, 2013, p. 8)

Segundo Valle (2011, p. 43), a "ideia de governança como atributo desejável à administração pública" remonta ao início dos anos 90, quando o Banco Mundial a definiu como “a maneira pela qual o poder é exercido na administração dos recursos sociais e econômicos de um país, visando ao desenvolvimento". (WORLD BANK, 1992, p. 1)

No entanto, a ideia de governança possui uma acepção mais abrangente, no sentido de que deve ser pensada como processo, sem ser circunscrita aos aspectos gerenciais e administrativos stricto sensu das rotinas dos órgãos públicos. Essa noção engloba o modus operandi das políticas governamentais, que, por sua vez, abarcam "desde a formatação do processo político-decisório, até os mecanismos democráticos de avaliação, sempre tendo em conta a articulação e cooperação entre parceiros sociais e políticos que possam concorrer para a superação das insuficiências do modelo estatal”. (VALLE, 2011, p. 42)

Para o exercício da governança, Valle (2011, p. 142-153) elenca, então, as seguintes condições: 1) colaboração da administração com a organização da cidadania; 2) administração que dialoga; 3) a importância do elemento técnico na construção da decisão administrativa; e 4) construção da confiança, por meio da governança e accountability.

E destaca, também, alguns elementos nucleares do conceito de governança:

1. o reconhecimento da importância seja das regras formais (constituição, leis, regulamentos), quanto daquelas informais (códigos de ética, costumes); 2. a abertura ao concurso de estruturas que extrapolam as relações de mercado; admitindo que não só as redes de cooperação, mas também as hierarquias (como aquelas próprias à burocracia) possam concorrer como facilitadores, nas circunstâncias apropriadas; 3 . aplicação não só da lógica de meios e resultados, inputs e outputs, assumindo que as 
características dos principais processos de interação social (transparência, integridade, inclusão) possam se apresentar como valor por si mesmas; e 4. o reconhecimento de que o processo de escolha pública é inerentemente político, voltado à mediação de distintos segmentos que pretendem exercer poder e fazer prevalecer seus interesses sobre os demais - portanto, não se trata de disputa a ser ponderada exclusivamente no âmbito do managerialismo ou de elites profissionais.

Como se vê, sem abdicar da importância do concurso da técnica, a ideia de governança atrai a noção de pluralismo, a valorização da interação social e o caráter político das escolhas públicas, como elementos indissociáveis de um modo de desenvolver a administração pública, trazendo à reflexão os meios institucionais e relacionais nesse modo de gerir a coisa pública. (VALLE, 2011, p. 42-43)

Ao abordar o contexto histórico que provocou a incorporação desses novos conceitos pelo direito administrativo, Moreira Neto lembra que:

[...] tanto uma boa administração quanto a governança em condições de realiza-la só passaram a interessar aos juristas depois de uma impressionante revolução conceitual no segundo pós-guerra, levando o Direito Administrativo a superar o âmbito do Estado nacional, no qual se originou, para, sem deixar de ser sua importante pilastra, tornar-se europeu e global, transcendendo os ordenamentos exclusivamente dependentes da autoridade legiferante dos Estados como expressão de suas soberanias, para se tornar um Direito cada vez mais consensual, negociado, democratizado, mundializado e independente de políticas nacionais. (MOREIRA NETO, 2011b, p. 13)

Nessa linha, a interdisciplinaridade torna-se imprescindível tanto para o progresso do direito administrativo, quanto para o direito em geral, diante da necessidade de contestação de uma metodologia isolacionista de estudo, de caráter tipicamente escolástico, dogmático e formalista. Essa postura, de uma ciência pretensamente pura e ideologicamente neutra, decorrente do positivismo exclusivista, terminou ocasionando o atraso do direito em relação aos demais ramos do conhecimento humano. (MOREIRA NETO, 2011b, p. 14-15)

Essa necessária multidisciplinaridade faz com que a racionalidade jurídica tenha que dialogar de maneira permanente e harmônica com a racionalidade administrativa que, por sua vez, corresponde a um discurso extrajurídico: Um direito fundamental à boa administração identificado com a governança
emprestará da racionalidade gerencial algo dos vetores do eficientismo voltado à
práxis, mas não abdicará de sua pretensão normativa, como articulador das já
referidas "regras do jogo", que se aplicará ao processo de construção da decisão
coletiva desejado pela governança. A palavra de ordem passa a ser integração das
racionalidades, para superar as limitações do conhecimento jurídico. (VALLE, 2011,
p. 118)

E esse diálogo é necessário não apenas com a racionalidade administrativa, mas sim com todos os demais discursos extrajurídicos envolvidos, o que pode e deve ser feito por meio de pontes de transição ${ }^{6}$ que liguem as diversas racionalidades envolvidas.

\footnotetext{
6 Neves (2009, p. 50-51) sustenta a necessidade de uma racionalidade transversal entre a pluralidade de sistemas (jurídicos e extra-jurídicos) existentes a partir da ideia de pontes de transição, por meio da qual é possível a construção de um diálogo entre essas diversas esferas de comunicação, cada uma com pretensão de universalidade.
} 


\title{
3 A FUNÇÃO DE CONTROLE DA ADMINISTRAÇÃO PÚBLICA BRASILEIRA
}

Não existe administração sem controle, de forma que uma atividade é inerente à outra. E na administração pública não é diferente, sujeitando-se ela a uma multiplicidade de controles, que têm como intuito evitar que se desvie dos seus objetivos. Esses controles englobam tanto aspectos de conveniência e oportunidade como de legalidade e legitimidade. (FERREIRA JÚNIOR, 2015, p. 71)

De acordo com Ferreira Júnior (2015, p. 71), a preocupação quanto à necessidade de controle dos atos estatais e de uma função específica para a execução dessa tarefa vem de longe. Aristóteles já demonstrava essa percepção, quando, ao tratar da distribuição das funções de governo, previa a existência de uma espécie de corte de contas ${ }^{7}$ :

Considerando, porém, que muitas, para não dizer todas, dessas funções movimentam grandes somas de dinheiro, existe a necessidade de que um outro órgão cuide da prestação de contas e da auditoria deles, não tendo nenhuma outra função além dessa. Estes funcionários são conhecidos como examinadores, auditores, contadores, controladores. (ARISTÓTELES, 2007, p. 231)

No texto de número 51 da obra $O$ Federalista, pode ser extraído o seguinte trecho que evidencia a necessidade de controle sobre a administração pública:

\begin{abstract}
Se os homens fossem anjos, não haveria necessidade de governo; e se anjos governassem os homens, não haveria necessidade de meio algum externo ou interno para regular a marcha do governo: mas, quando o governo é feito por homens e administrado por homens, o primeiro problema é pôr o governo em estado de poder dirigir o procedimento dos governados e o segundo obrigá-lo a cumprir as suas obrigações. A dependência em que o governo se acha do povo é certamente o seu primeiro regulador; mas a insuficiência desse meio está demonstrada pela experiência. (HAMILTON; MADISON; JAY, 2003, p. 318)
\end{abstract}

Ferraz (1999, p. 111-112) aborda a gênese e evolução histórica do controle das finanças públicas, 8 remetendo sua origem embrionária à época do Código Indiano de Manu, século XIII a.C., que previa expressamente, no Livro relativo ao Direito Público, disposições (zlotas, versículos) sobre a administração financeira e instrumentos de fiscalização. $\mathrm{O}$ autor aponta, ainda, a existência na China antiga de um órgão de fiscalização responsável por toda a atividade estatal, incluída a do rei. No entanto, sustenta que foi entre os gregos (logistas) e os romanos (questores) que a atividade fiscalizadora estatal foi institucionalizada, servindo de experiência para as gerações subsequentes.

\footnotetext{
7 Aristóteles (2007, p. 177) aponta oito espécies de tribunais existentes na parte judiciária do governo: 1) tribunal de contas; 2) que julga os danos causados à Cidade; 3 ) que julga as ofensas à constituição; 4) para decidir disputas entre os magistrados e os cidadãos comuns quanto a penas; 5) para decidir quanto a questões relativas a contratos entre particulares; 6) os que julgam os homicídios [...]; 7) tribunais para estrangeiros, nos casos entre eles e os cidadãos; e 8) tribunais para pequenas causas.

8 Lopes (1947) faz uma análise da evolução histórica da fiscalização no mundo, a partir da antiguidade oriental, passa pela antiguidade clássica e pelo período medieval, até chegar aos tempos contemporâneos e ao Brasil, onde centra seus estudos na instituição Tribunal de Contas.
} 
De forma que, por função de controle, deve-se entender aquela realizada pela Administração Pública sobre seus próprios atos. Esse controle pode ser classificado em interno e externo. O interno é aquele exercido pelo próprio Poder sobre seus atos, enquanto que o externo é realizado por outro órgão da Administração Pública que goze de autonomia e independência para tanto.

O controle externo é um fenômeno jurídico institucional observado no mundo, sendo adotado por muitos países algum modelo de controle governamental independente sobre suas contas públicas. ${ }^{9}$

No Brasil, o controle da administração pública tem previsão constitucional e é tratado, principalmente, nos arts. 70 a 75 da CRFB/88, na Seção XIV, que trata da fiscalização contábil, financeira e orçamentária, posicionada dentro do capítulo I, que, por sua vez, versa sobre o Poder Legislativo. Além disso, pode ser encontrada referência ao controle também na parte em que a CRFB/88 trata dos municípios, mais especificamente no seu art. 31.

Em virtude do princípio da simetria, as disposições da Constituição Federal que tratam do controle da administração pública são de reprodução obrigatória pelos Estados e Municípios ${ }^{10}$ nos textos de suas Constituições Estaduais e Leis Orgânicas Municipais.

No Brasil, o controle externo da administração pública é exercido pelo Congresso Nacional e pelos Tribunais de Contas, cabendo ao primeiro um controle político, enquanto que ao segundo, um controle técnico, não apenas jurídico, mas também administrativo, econômico, contábil e operacional.

Equivoca-se quem sustenta que o Parlamento é o titular absoluto do controle. Essa visão encontra raízes históricas no fato de que os seus membros são representantes do povo, a quem, em última análise, devem ser prestadas contas dos recursos públicos empregados. No entanto, esse enfoque não mais se justifica hodiernamente, tornando-se anacrônica a atribuição da titularidade exclusiva do controle nas mãos dos parlamentares, não apenas em virtude da perda de condições técnicas e de tempo das casas parlamentares11, mas também pelo fato de a transparência e o controle social ganharem cada vez mais força e espaço na sociedade contemporânea. (FERREIRA JÚNIOR, 2015, p. 101-102)

\footnotetext{
9 Muito embora não haja um padrão de estruturação, Gualazzi (1992, p. 34-36) procura sistematizar os modelos de controle externo existentes no mundo, a partir dos seguintes critérios: a) grau de independência do órgão de controle em relação ao poder político (Parlamento ou Governo); b) composição estrutural do órgão; c) a amplitude das competências; e d) a titularidade eventual de funções jurisdicionais.

$10 \mathrm{O}$ art. $31, \S 4^{\mathrm{o}}$, da $\mathrm{CRFB} / 88$ vedou a criação de Tribunais e Conselhos de Contas no âmbito municipal, permitindo, no entanto, a manutenção dos dois únicos então existentes, Rio de Janeiro e São Paulo.

11 Acerca da atual crise de legitimidade do Parlamento e sobre a institucionalização de um novo conjunto de funções constitucionais, que são político-partidariamente neutras, frutos de significativas modificações juspolíticas na teoria dos interesses públicos, vide Moreira Neto (2011a, p. 6772).
} 
Entender o titular da função de controle apenas como o Parlamento tem como consequência a redução dessa tarefa tão somente ao seu aspecto político, quando o seu objeto abrange também o enfoque técnico, o qual cabe aos Tribunais de Contas. (FERREIRA JÚNIOR, 2015, p. 101)

Ocorre que, no Brasil, os Tribunais de Contas padecem de um verdadeiro déficit de legitimidade plena, caracterizado pela insuficiência na aferição das três formas de legitimação, ${ }^{12}$ a saber: a) a originária, haja vista uma série de anomalias na nomeação de seus membros Ministros ou Conselheiros a que se assiste frequentemente; a corrente, a partir do momento em que se constata a frustração das expectativas dos cidadãos, quanto ao desempenho das Cortes de Contas; e, finalmente, a finalística, com base na percepção negativa que a sociedade tem no que diz respeito aos resultados obtidos por meio da atuação dessas instituições. (FERREIRA JÚNIOR, 2015, p. 118)

Esse déficit de legitimidade tem como consequências, de um lado, a atrofia do controle externo e, como contrapartida, a hipertrofia de outros sistemas como, por exemplo, o judiciário $^{13}$ e o Ministério Público. (FERREIRA JÚNIOR, 2015, p. 119)

E uma das razões desse déficit de legitimidade ${ }^{14}$ reside no tipo de controle que tradicionalmente é exercido no Brasil, associado à cultura do burocratismo e do formalismo excessivos e irracionais e que se reflete não apenas na atividade do controle administrativo, mas também na gestão, o que contribui para a ineficiência e ineficácia de ambos, em um processo negativo de retroalimentação. (FERREIRA JÚNIOR, 2015, p. 127-132)

Esse diagnóstico que, como dito, não se aplica somente à gestão, mas também ao controle, implica a necessidade de superação de uma concepção formalista de controle administrativo-financeiro e do estabelecimento de um novo paradigma, condizente com a boa governança pública. Em outras palavras, é preciso que os Tribunais de Contas assumam o protagonismo do bom controle das contas públicas. (FERREIRA JÚNIOR, 2015, p. 127)

\footnotetext{
12 Sobre a legitimidade plena da ação do Poder Público, que pode ser compreendida por meio da distinção que se faz entre as legitimidades originária, corrente e finalística ou teleológica, vide Moreira Neto (2005, p. 90-92).

13 A respeito do crescimento da autoridade do Judiciário, em especial do STF, em detrimento dos demais poderes, vide Vieira (2008), que utiliza o termo supremocracia para diagnosticar o fenômeno da mudança de equilíbrio do sistema de separação de poderes no Brasil, em que o Judiciário vem cada vez mais legislando e administrando. Discordando desse diagnóstico, Sundfeld e Domingos (2014, p. 18-23), após analisarem recentes decisões da Suprema Corte brasileira, sustentam que é exagero falar em supremocracia, já que o STF não apenas reconhece a legitimidade da administrocracia (ou seja, da Administração Pública como protagonista na construção de novas fórmulas jurídicas, na formatação de políticas públicas, enfim, na criação do novo direito público brasileiro), como está disposto a defendê-la em seus julgados. Por fim, os autores reconhecem a importância do ativismo retórico do STF como a verdadeira contribuição no atendimento às demandas sobre políticas públicas e direitos sociais.

14 Após sustentar a necessidade de superação da teoria clássica da divisão tripartite de poderes, com o reconhecimento constitucional expresso da função de controle como um Poder autônomo e soberano, a exemplo

do que vem sendo feito em alguns países, Ferreira Júnior (2015, p. 49-132) identifica, também, como uma das razões para esse déficit de legitimidade, o processo de escolha dos membros dos Tribunais de Contas, assim como o desequilíbrio técnico e político na composição do órgão.
} 
O controle, se mal realizado, ao invés de ser um inimigo das mazelas da administração pública, termina por se tornar um aliado delas e um incentivador da ineficiência, ineficácia e corrupção. (FERREIRA JÚNIOR, 2015, p. 127)

Esse também foi o diagnóstico de Gordillo, ao analisar o controle da Administração Pública na América Latina:

Consideramos, com base na experiência de nossos países, que estes controles são inaptos para produzir mudanças de mentalidade, de atitudes, de comportamentos e crenças; ao contrário, podem estar retroalimentando o sistema coadjuvando a crescente regulamentação da atividade pública, realçando a formalidade em detrimento da eficácia. (GORDILLO, 1981, p. 79)

É essa cultura arraigada da administração pública tradicional, centrada em uma burocracia inútil e, excessivamente, em procedimentos, ao invés de focada em resultados, alimentadora de um círculo vicioso entre a gestão e o controle administrativos ineficientes e ineficazes, que precisa ser rompida. (FERREIRA JÚNIOR, 2015, p. 128)

Para Lima (2014), os tradicionais métodos de controle da administração pública “estão mortos, mas insepultos. Calcados na tradição formalista e numa visão estrita da legalidade, tais métodos tornaram-se tão obsoletos como as missas em latim, mas sem a beleza dos cantos gregorianos". Essa aproximação não mais atende às aspirações de uma sociedade que reivindica do Estado qualidade na prestação dos serviços, cuidado na aplicação dos recursos e seriedade no trato da coisa pública. Os cidadãos demandam resultados melhores nas políticas públicas, o que o controle formalista é incapaz de fazer.

E isso se aplica também à prevenção e ao enfrentamento da corrupção e dos desvios de recursos na administração pública:

Enquanto as fraudes ocorrem em transferências bancárias milionárias em paraísos fiscais processadas em poucos cliques nos teclados de laptops ou smartphones, o controle formalista ainda se concentra em carimbos e rubricas. Como numa piracema às avessas, sua rede só alcança girinos e bagrinhos, deixando livres os peixes grandes e gordos, cevados no assalto ao erário. A exemplo dos mortos de Antares na obra de Érico Veríssimo, o cadáver do controle formalista perambula ali e acolá, em decomposição nauseabunda, defunto sem sepultura a assombrar os viventes.

A bem da verdade, sua certidão de óbito foi lavrada pela Constituição de 1988 que estipulou que o controle externo da gestão pública, exercido pelo Legislativo e pelos Tribunais de Contas, observaria, além da legalidade, também a legitimidade e a economicidade dos atos e contratos governamentais. E mais: a Carta Magna previu que a fiscalização não seria mais restrita a aspectos orçamentários e contábeis, mas também financeiros, patrimoniais e operacionais. O constituinte de 1988 anteviu o futuro e lançou as bases de um controle voltado para a efetividade da gestão pública $[. .$.

Mas então, o que explica a permanência do controle formalista, em descompasso com a Lei Maior que já completou um quarto de século? Ora, o arraigado conservadorismo que permeia os círculos de poder tão magistralmente descritos por Raymundo Faoro em Os Donos do Poder. Trata-se da obstinada resistência daqueles 
que por décadas se habituaram a fazer dos cargos públicos atalhos para o enriquecimento pessoal e de seus clãs, e também o inconformismo dos recémchegados a postos de comando e que não admitem o saneamento da vida pública "logo agora que chegou a sua vez". Todos se coligam como insurgentes do Velho Regime, intransigentes no propósito de fazer letra morta do modelo constitucional de controle externo.

Dissimulados, não assumem o que de fato pretendem: a perpetuação do controle formalista, tão conveniente, por sua ineficácia, para os larápios do tesouro.

$[\ldots]$

É hora de sepultar o controle que não funciona e assegurar aos brasileiros controles mais técnicos e inteligentes, pautados na efetividade e que contribuam para a melhoria da gestão pública. (LIMA, 2014, grifo nosso)

Para Campos (1990, p. 42-46), o frágil controle que os Tribunais de Contas têm exercido sobre a burocracia soma-se à incipiência da malha institucional da sociedade, contribuindo para que a administração pública permaneça imune à accountability. Além disso, a autora identifica uma correspondência entre os traços do contexto político e cultural da administração pública brasileira e as características dessa burocracia.

Da parte contextual, destacam-se a debilidade das instituições e os baixos níveis de organização da sociedade, de expectativa quanto à atuação do governo e de participação popular (o povo como objeto da política pública). Na parte da burocracia, apontam-se como traços mais significativos: a imunidade a controles externos; a falta de transparência; o baixo nível de preocupação com o desempenho; a marcada orientação para meios e procedimentos; e a tendência exagerada para regras e normas e o desrespeito pelo seu cumprimento (formalismo). (CAMPOS, 1990, p. 42)

Dessa forma, seriam três as principais deficiências dos controles burocráticos no Brasil. Em primeiro lugar, o alto formalismo dos controles e a sua absoluta ineficiência no que diz respeito à accountability. Em segundo, mostram-se fortemente focados nos meios e pouco interesse quanto aos fins, aos resultados ou às consequências dos programas públicos. Em terceiro, não consideram as peculiaridades dos diferentes órgãos públicos e de suas missões e o que isso representa em termos de diferentes processos de controle e de avaliação, preocupando-se excessiva e indevidamente com a uniformização. (CAMPOS, 1990, p. 46-47) Campos (1990, p. 48) conclui, ainda, pela necessidade de ampliação dos controles burocráticos em dois sentidos. Primeiro, através de uma redefinição conceitual de controle e avaliação, com o objetivo de incluir outras dimensões de desempenho, tais como eficácia, efetividade, justiça social e política. E segundo, pela expansão do número de controladores e da sua representatividade, reforçando, dessa forma, a própria legitimidade do controle. 
Diante do exposto, resta claro que a concretude do princípio da justiça financeira e a efetivação do direito fundamental à boa administração dependem do abandono de uma cultura arraigada no Brasil de administração pública burocrática autorreferente, orientada para os seus próprios processos e para suas próprias necessidades e perspectivas, e, consequentemente, da adoção de práticas de gestão pública direcionadas à obtenção de resultados e focadas no destinatário final dos serviços, ou seja, nos cidadãos, através da disseminação e sedimentação de conceitos de boa governança, o que somente é possível também a partir de uma nova visão de controle público. (FERREIRA JÚNIOR, 2015, p. 127)

\section{O BOM CONTROLE PÚBLICO COMO DIREITO FUNDAMENTAL E AS CORTES DE CONTAS COMO TRIBUNAIS DA BOA GOVERNANÇA}

De acordo com Freitas (2014, p. 14), “o excesso de controle equivale ao não controle", o que gera a supressão da inovação e da maleabilidade, requisitos de uma gestão eficiente e eficaz. Para tanto, é preciso combater "o controle pesado, burocratizante, oneroso, labiríntico e violador da interdependência dos Poderes”. E vaticina lançando mão da metáfora de que "de nada serve o simplismo de amarrar Ulisses ao mastro para impedi-lo de sucumbir ao canto das sereias".

O diagnóstico de Conti também acompanha essa linha ao advertir que:

O sistema de fiscalização financeira e orçamentária, atento à Constituição Federal, que em seu artigo 70 preconiza a fiscalização da legitimidade e economicidade do dinheiro público, e no artigo 37, caput, erige a eficiência à condição de princípio que rege a administração pública, já está há muito tempo desenvolvendo técnicas voltadas a uma fiscalização da qualidade do gasto público. Infelizmente ainda não acolhidas pelos sistemas de fiscalização de todos os entes da federação, essas técnicas certamente serão implementadas num futuro próximo, que se espera breve.

[...]

Aperfeiçoar a qualidade do gasto público é fazer mais com menos, ou seja, produzir mais benefícios públicos com menos recursos, o que exige, entre outras medidas além das já mencionadas, a modernização da gestão, aumento da participação popular nas decisões sobre o gasto público, maior transparência e controle. São inúmeras as providências a serem tomadas nesse sentido, que exigem não somente uma nova legislação, adaptada aos novos tempos e técnicas, mas também, e principalmente, uma mudança de cultura na administração pública. No mais das vezes preocupada com aspectos formais da despesa pública, a burocracia acaba perdendo o foco naquilo que realmente importa, que é atender a necessidade pública, transformando-se numa verdadeira "burrocracia", de todos conhecida e odiada. (CONTI, 2013) 
O direito fundamental à boa administração e governança, inclusive como consectário do princípio da justiça financeira, dentre outros, clama, portanto, a adoção de novos mecanismos de gestão pública, o que, por outro lado, exige uma evolução no controle.

Esse novo paradigma de controle é o que Ferreira Júnior e Olivo chamam de bom controle público, para quem:

[...] uma nova práxis administrativa conclama uma nova práxis de controle, que pode ser sintetizada na expressão bom controle público, signo de um controle racional, abrangente, substancial, eficiente, eficaz, focado em resultados, avesso a formalismos inúteis e ao burocratismo paralisante, que não se limite à legalidade, mas investigue a legitimidade da gestão por meio, inclusive, da sindicabilidade da discricionariedade administrativa. (2014, p. 211 , grifo no original)

Para Ferreira Júnior (2015, p. 134), se há um direito fundamental à boa administração pública e se ele foi alçado à condição de princípio cogente do Estado Constitucional, forçoso afirmar que existe também, até como consectário lógico deste, um direito fundamental ao bom controle público, que também deve ser interpretado como uma norma implícita e de eficácia imediata em nosso ordenamento jurídico. Na visão do autor:

[...] o bom controle público sobre a administração pode ser conceituado como o controle preocupado com a legalidade, mas também com a legitimidade, economicidade e com a concretude dos princípios constitucionais; retrospectivo e prospectivo; reativo e proativo; vigoroso sem ser excessivo; repressor de más condutas e promotor de boas; que atue sobre os comportamentos omissivos e comissivos; salutar, dialógico, inteligente e racional; contextual e global, mas sem perder de vista as partes que formam o todo; imparcial, proporcional, substancial e profundo; que considere a seletividade e materialidade em suas análises; eficiente, eficaz e efetivo; focado em sustentabilidade e em resultados; avesso a formalismos desnecessários, mas sem desprezar a importância dos meios; que enfrente o demérito das escolhas por meio da sindicabilidade profunda da discricionariedade administrativa.

Um controle rigoroso, porém maleável; que estimule a criatividade e a inovação, sem gerar no administrador o temor na escolha das melhores decisões; que não concentre as consequências de sua ação apenas na figura do gestor, mas que a distribua por toda a cadeia de responsabilidades da administração, gerando o comprometimento de todos; cuja visão não se limite ao curto prazo, contemplando o médio e o longo termo em suas avaliações; preocupado com a transparência e a participação social; que contemple a integração, a coordenação e o compartilhamento da ação com outras instituições; moderno, atento e adepto às novas tecnologias; que consiga ser, ao mesmo tempo, causa e consequência da boa administração e governança pública, servindo de alimentador de práticas sadias na administração pública e também sendo por elas nutrido.

Enfim, é a antítese do controle ineficiente e ineficaz abordado anteriormente, ou seja, do mau controle, e que, por essa razão, produz justamente os efeitos contrários aos gerados por este. É um controle que mantém uma relação de simbiose com o controlado, que alimenta um círculo virtuoso de boas práticas na administração, promovendo, dessa maneira, a boa governança pública. (FERREIRA JÚNIOR, 2015, p. 135)

A partir dessa noção do bom controle público, é possível inferir que, para além da tarefa constitucional de guardiães das contas públicas, os Tribunais de Contas devem 
materializar essa nova concepção de controle, assumindo, de maneira proativa, a missão, também constitucional, de promotores da boa governança no setor público ${ }^{15}$, rompendo, assim, com a lógica perversa do mau controle.

\section{CONCLUSÃO}

A partir da valoração do princípio da justiça financeira e do direito fundamental à boa administração e governança pública como pilares fundamentais do Estado Constitucional, o presente trabalho procurou redesenhar a definição do controle público, de forma que os Tribunais de Contas e a função de Controle assumam posição protagonista no cenário institucional brasileiro.

As mazelas do controle tradicional terminaram por contribuir para a construção de uma visão negativa da sociedade sobre as Cortes de Contas como instituição. Porém, a partir de uma nova visão da administração pública, abre-se espaço para uma concepção de controle decorrente daqueles valores fundantes do Estado Democrático de Direito, dando surgimento, então, ao direito fundamental ao bom controle público.

O bom controle público atua, dessa forma, como canal condutor da boa administração e governança pública, mantendo com ela uma relação simbiótica e de retroalimentação de boas práticas de governança, de modo a dar concretude à carga principiológica norteadora do Estado brasileiro.

A função de controle passa, então, a ser concebida de maneira a ultrapassar os limites do controle tradicionalmente feito, exsurgindo dessa ruptura um novo paradigma sintetizado na expressão bom controle público, resultante da materialização dos valores da justiça financeira e da boa administração e governança pública e, como tais, alçado também à condição de direito fundamental de eficácia imediata em nosso sistema jurídico.

Esse bom controle público pode ser resumido como a antítese do controle ineficiente e ineficaz, ou seja, o oposto do mau controle, produzindo, justamente, os efeitos contrários aos gerados por este.

A legitimação plena da função de controle como Poder de Estado, por meio da superação do déficit de que padece, pressupõe o seu redimensionamento material e procedimental em sintonia com essa nova concepção do bom controle público.

\footnotetext{
15 Para tanto, a partir dessa concepção de bom controle público, Ferreira Júnior (2015, p. 133-224) prognostica a necessidade de um redimensionamento material e de uma redefinição procedimental como novos paradigmas de atuação das Cortes de Contas brasileiras, mais consentâneos com a ideia de boa administração e governança pública.
} 


\section{REFERÊNCIAS}

ARISTÓTELES. Política. São Paulo: Martin Claret, 2007.

BRASIL. Constituição (1988). Constituição da República Federativa do Brasil: promulgada em 5 de outubro de 1988. Disponível em:

<http://www.planalto.gov.br/ccivil_03/Constituicao/Constituicao .htm>. Acesso em: 29 jun. 2014.

CAMPOS, Anna Maria. Accountability: quando poderemos traduzi-la para o português? Revista de Administração Pública, v. 24, n. 2, fev./abr. 1990, p. 30-50. Rio de Janeiro: EBAPE/FGV, 1990.

CARBONELL, Miguel. Prólogo. Nuevos tiempos para el constitucionalismo. In: Neoconstitucionalismo. Madrid: Trotta, 2003.

CARVALHO FILHO, José dos Santos. Manual de Direito Administrativo. 25. ed. rev., ampl. e atual. São Paulo: Atlas, 2012.

CONTI, José Mauricio. Responsabilidade orçamentária precisa de melhorias. Conjur. Disponível em: <http://www.conjur.com.br/2013-mar-12/contas-vista-qualidade-fiscalresponsabilidade-orcamentaria>. Acesso em: $1^{\circ}$ out. 2013.

COSTA, Paulo Jorge Nogueira da. O Tribunal de Contas e a boa governança. Contributo para uma reforma do controle financeiro externo de Portugal. 2012. $601 \mathrm{f}$. Tese (Doutorado em Direito) Curso de Pós-Graduação em Direito. Universidade de Coimbra. Disponível em: $<$ https://estudogeral.sib.uc.pt/bitstream/10316/21154/3/O\%20Tribunal\%20de\%20Contas\%20 e\%20a\%20Boa\%20Governan\%C3\%A7a.pdf>. Acesso em: 15 out. 2013.

FERRAZ, Luciano de Araújo. Controle da administração pública: elementos para a compreensão dos Tribunais de Contas. Belo Horizonte: Mandamentos, 1999.

FERREIRA JÚNIOR, Adircélio de Moraes. O bom controle público e as cortes de contas como tribunais da boa governança. 2015. Dissertação (Mestrado em Direito). Universidade Federal de Santa Catarina. Disponível em:

<http://www.tce.sc.gov.br/sites/default/files/Disserta\%C3\%A7\%C3\%A3o\%20Adirc\%C3\%A 9lio $\% 200 \% 20$ Bom $\% 20$ Controle $\% 20 \mathrm{P} \% \mathrm{C} 3 \%$ BAblico $\% 20 \mathrm{e} \% 20$ as $\% 20$ Cortes $\% 20 \mathrm{de} \% 20 \mathrm{Cont}$ as\%20como\%20Tribunais\%20da\%20Boa\%20Governan.pdf>. Acesso em: 10 jul. 2015.

FERREIRA JÚNIOR, Adircélio de Moraes; OLIVO, Luis Carlos Cancellier de. O controle das receitas públicas pelos tribunais de contas como corolário do princípio da justiça financeira e do direito fundamental à boa administração e governança. In: Direito e administração pública II. Organização CONPEDI/UFPB. Florianópolis: CONPEDI, 2014. Disponível em: < http://www.publicadireito.com.br/artigos/?cod=a7468b046115fc3c >. Acesso em: 27 jan. 2015.

FREITAS, Juarez. Direito fundamental à boa administração pública. 3. ed. São Paulo: Malheiros, 2014.

GORDILLO, Augustín. Problemas del control de la administración pública en América Latina. Madrid: Civitas, 1981.

GUALAZZI, Eduardo Lobo Botelho. Regime jurídico dos Tribunais de Contas. São Paulo: Revista dos Tribunais, 1992. 
HAMILTON, Alexander; MADISON, James; JAY, John. O federalista. Belo Horizonte: Líder, 2003.

IFAC. International Federation of Accountants. Governance in the public sector: consultation draft for an international framework, 2013. Disponível em:

<http://www.ifac.org/sites/default/files/publications/files/Good-Governance-in-the-PublicSector.pdf > . Acesso em: 15 mai. 2014.

LIMA, Luiz Henrique. Formalismo ou efetividade? ATRICON - Associação dos Membros dos Tribunais de Contas do Brasil [internet]. Brasília, 2014. Disponível em:

<http://www.atricon.org.br/artigos/formalismo-ou-efetividade/>. Acesso em: 15 jul. 2014.

LOPES, Alfredo Cecílio. Ensaio sôbre o Tribunal de Contas. São Paulo, 1947.

MALLÉN, Beatriz Tomás. El derecho fundamental a una buena administración. 1. ed. Madrid: Instituto Nacional de Administración Pública, 2004.

MATIAS-PEREIRA, José. Manual da gestão pública contemporânea. 2. ed. São Paulo: Atlas, 2009.

MOREIRA NETO, Diogo de Figueiredo. Democracia e contrapoderes. RDA-Revista de Direito Administrativo, Rio de Janeiro, v. 258, p. 47-80, set./dez. 2011 a.

O parlamento e a sociedade como destinatários do trabalho dos Tribunais de Contas. In: O Novo Tribunal de Contas: órgão protetor dos direitos fundamentais, Alfredo José de Souza et al., p. 77-130, 3. ed. Belo Horizonte: Fórum, 2005.

Prefácio. In:VALLE, Vanice Regina Lírio do. Direito fundamental à boa administração e governança. Belo Horizonte: Fórum, 2011 b.

NEVES, Marcelo. Transconstitucionalismo. São Paulo: Martins Fontes, 2009.

PORTUGAL. Constituição (1988). Constituição da República Portuguesa: aprovada em 2 de abril de 1976. Disponível em:

<http://www.parlamento.pt/Legislacao/Paginas/ConstituicaoRepublicaPortuguesa.aspx>. Acesso em 28 jun. 2014.

RODRÍGUEZ-ARANA MUÑOZ, Jaime. La buena Administración como principio y como derecho fundamental en Europa. Misión Jurídica Revista de Derecho e Ciencias Sociales, n. 6, jan./dez. 2013, p. 23-56. Bogotá: 2013. Disponível em:

$<$ http://www.unicolmayor.edu.co/revistajuridica/pdf/sexta_edicion/1_LA_BUENA_ADMINI STRACIu00D3N.pdf>. Acesso em 19 ago. 2015.

SUNDFELD, Carlos Ari; DOMINGOS, Liandro. Supremocracia ou administrocracia no novo direito público brasileiro? Fórum Administrativo - FA, Belo Horizonte, ano 14, n 159, p. 1823, maio 2014.

TCU. Tribunal de Contas da União. Referencial básico de governança. Brasília: TCU, 2013. Disponível em: <http://portal2.tcu.gov.br/portal/pls/portal/docs/2616066.PDF>. Acesso em: 19 fev. 2014.

TORRES, Ricardo Lobo. Tratado de direito constitucional financeiro e tributário, volume V: o orçamento na Constituição. 2. ed. rev. e atual. Rio de Janeiro: Renovar, 2000.

VALLE, Vanice Regina Lírio do. Direito fundamental à boa administração e governança. Belo Horizonte: Fórum, 2011. 
VERGOTTINI, Giuseppe. Diritto costituzionale. 4. ed. Pádua, CEDAM, 2004.

VIEIRA, Oscar Vilhena. Supremocracia. Revista Direito GV, vol.4, n. 2, São Paulo, jul./dez. 2008. Disponível em:

<http://www.scielo.br/scielo.php?script=sci_arttext\&pid=S1808-24322008000200005>. Acesso em: 11 jan. 2015.

WILLEMAN, Marianna Montebello. O princípio republicano e os Tribunais de Contas. Interesse Público - IP. Belo Horizonte, n. 50, ano 10, julho/agosto 2008. Disponível em: <http://www.bidforum.com.br/bid/PDI0006.aspx?pdiCntd=54797>. Acesso em: 21 jun. 2013.

WORLD BANK. Governance and development. Washington: World Bank, 1992.

$<$ http://www-

wds.worldbank.org/external/default/WDSContentServer/WDSP/IB/1999/09/17/000178830_9

8101911081228/Rendered/PDF/multi_page.pdf >. Acesso em: 11 jul. 2014. 